\title{
PEREMPUAN DAN ADAT PERKAWINAN (STUDI TENTANG MARGINALISASI PEREMPUAN DALAM JUJURAN ADAT ISTIADAT PERKAWINAN DI NIAS)
}

\author{
Efentinus Ndruru \\ Prodi Magister Sosiologi \\ Fakultas Ilmu Sosial dan Ilmu Politik, Universitas Sumatera Utara \\ email: efent_28des@yahoo.com
}

\begin{abstract}
The study of gender studies (gender mainstreaming) today is a response to the phenomenon of domestic violence. Violence is inseparable from the dominance of men who are constructed in patriarchal culture. Women's research and marriage customs that impact on the marginalization of women in Nias is a continuous series of critics for gender observers, especially in the practice of marriage customs. There is a tendency of "women as purchased parties" to encourage the strengthening of arguments against acts of violence in the household. So in this case study, researchers dig information by conducting in-depth interviews, observations and literature review to find joints of violence that are not generally accepted. The results show that women in the marriage customary process are passive and not yet fully involved in the process of determining the marriage vows. The male side as a "buyer" with a considerable debt burden spawned a new problem that has an impact on wife violence. Therefore, it is necessary to socialize gender awareness as a means to oppose the maginalization experienced by women.
\end{abstract}

Keyword: Gender, Nias, Maginalization, and Marriage Tradition.

\section{Pendahuluan}

Isu marginalisasi perempuan sesungguhnya bermuara dari persoalan ketimpangan gender yang telah melahirkan gap gender yang berakibat buruk baik dari sisi sosial, ekonomi maupun politik terhadap perempuan. Ketimpangan gender dalam masyarakat Indonesia diwujudkan dalam pelbagai bentuk yaitu; kekerasan, marginalisasi, subordinasi, stereotipe dan beban ganda (Fakih, 1996; Holzner, 1997). Mengenai fenomena ketimpangan gender yang dialami oleh perempuan maka berbagai studi sudah banyak dilakukan di Indonesia, antara lain: studi tentang kekerasan dalam rumah tangga (KDRT) yang dapat berbentuk fisik dan non fisik yang memperlihatkan kecenderungan, korbannya adalah perempuan (Ihromi, 2000; Komnas Perempuan, 2009).

Marginalisasi merupakan suatu fenomena ketimpangan gender yang banyak terjadi pada perempuan (miskin) di Indonesia, termasuk salah satunya masyarakat Nias. Berkenaan dengan persoalan tentang gender ini maka Fakih 
(1996) dan Abdullah (2001) dua akademisi laki-laki yang feminis memberikan suatu pandangan dan jawaban kritis. Keduanya menganalisis bahwa konsep gender akan menjadi suatu persoalan ketika perbedaan gender yang telah ada berproses dalam sistem sosial dan budaya berubah jadi suatu ideologi gender yang menciptakan nilai atau pandangan bias pada perempuan. Akibat yang ditimbulkannya di kemudian hari yaitu ketimpangan berupa adanya pandangan, perlakuan maupun berbagai tindakan terhadap kehidupan perempuan yang bersifat tidak adil di dalam masyarakatnya.

Persoalan marginalisasi perempuan dalam masyarakat Nias dipengaruhi oleh budaya patriakhi yang sangat kentaran, khususnya dalam tradisi adat perkawinan. Proses marginalisasi pada perempuan tidak terlepas dan terlekat pada peranan dari suatu sistem sosial yang dinyatakan dalam struktur sosial yang bernama" ideologi patriarki". Pandangan ini setidak-tidaknya diyakini oleh mayoritas feminis dan sebagai agenda penting untuk menyelesaikan problema ketimpangan gender yang ada di masyarakat. Sebagaimana yang dikatakan oleh feminis Walby (1990) mengenalkan bahwa sistem sosial yang menindas perempuan melalui struktur sosial itu adalah patriarki. Lebih spesifik lagi dia mengartikan patriarki sebagai sebuah sistem tentang struktur-struktur dan praktek-praktek yang di dalamnya laki-laki mendominasi, menindas dan menghisap perempuan.

PESADA (Perkumpulan Sada Ahmo) dalam penelitian tentang "memahami jujuran dalam hubungannya dengan pola Kekerasan Dalam Rumah Tangga (KDRT) terhadap perempuan Nias" menegaskan bahwa kekerasan dalam rumah tangga mempunyai hubungan dengan jujuran yang sering sekali berdampak pada utang. Sebagian perempuan Nias merasa bahwa utang membuat mereka menjadi miskin. Kemiskinan membuat ketegangan yang cukup tinggi dalam keluarga, ditambah dengan banyaknya kasus suami yang sering minum-minum dan mabuk, malas bekerja, sampai pada kecenderungan untuk berselingkuh dan main pukul (Sinaga, 2014).

Menurut Gulö (2015:169), bagi masyarakat Nias memiliki utang saat melangsungkan perkawinan merupakan hal yang lumrah. Paradigma semacam ini tersirat di dalam pepatah Nias: "sangötö idanö ba abasö" (mereka yang menyeberang sungai pasti basah). Pepatah Nias itu hendak mengatakan bahwa utang perkawinan merupakan utang yang tidak terelakkan; bahkan lumrah terjadi kepada siapapun yang akan menikah. Praktek semacam ini justru dikritisi oleh pihak gereja karena berdampak pada marginalisasi perempuan sebagai pihak "yang dibeli" oleh pihak laki-laki. Gereja menegaskan bahwa perempuan yang menikah dianggap sebagai "orang yang sudah dibeli", karena itu bisa diperlakukan sebagai warga kelas dua dalam keluarga. Situasi ini muncul dari jujuran yang sangat mahal, yang masih dipraktekkan di tengah masyarakat Nias (Sinode, 2010:81). Oleh sebab itu, perlu sebuah ulasan untuk mengkritisi problem sosial perempuan dalam hubungannya dengan adat istiadat perkawinan yang berdampak pada marginalisasi dari persepktif 
gender.

\section{TINJAUAN PUSTAKA}

Berbagai konsep gender dimaknai sebagai suatu perbedaan yang bukan biologis dan bukan kodrat (Wallace and Candida, 1991). Perbedaan biologis yakni perbedaan jenis kelamin (sex) adalah kodrat Tuhan dan oleh karenanya secara permanen berbeda. Sedangkan gender adalah perbedaan perilaku (behavioral differences) antara laki-laki dan perempuan yang dikonstruksi secara sosial, yakni perbedaan bukan kodrat atau bukan ketentuan Tuhan melainkan hasil olahan manusia (laki-laki dan perempuan) melalui proses sosial dan kultural yang panjang. Pemahaman konsep gender dari segi kultural dimaknai pula sebagai pembedaan (distinction) dalam peran, perilaku, mentalitas dan karakter emosional antara laki-laki dan perempuan yang berkembang dalam masyarakat. Dengan demikian gender merupakan harapan-harapan budaya (cultural expectations for women and men) dan sosial terhadap laki-laki dan perempuan (Fakih, 1996; Ihromi, 2000).

Menurut Fakih (1996) dan Murniati (2004) manifestasi dari ketidakadilan gender pada proses berikutnya juga menyebabkan lahirnya stratifikasi gender (gender stratification) dan penindasan gender (gender oppression). Akibat yang timbul dari manifestasi atau perwujudan dari stratifikasi dan penindasan gender salah satunya melahirkan marginalisasi ekonomi kaum perempuan. Selanjutnya Fakih (1996) memberikan analisis gendernya mengenai marginalisasi karena adanya sterotipe tertentu atas kaum perempuan dan itu menyumbang kepada subordinasi, kekerasan kepada kaum perempuan, yang akhirnya tersosialisasikan dalam keyakinan, ideologi dan visi kaum perempuan sendiri.

Menurut Megawangi (dalam Umar, 1999: 23) dalam konteks persoalan gender teori Sosial-Konflik banyak dipengaruhi oleh pemikiran Marx yang kemudian dilengkapi oleh F. Engels. Teori ini mengatakan perbedaan dan ketimpangan gender antara laki-laki dan perempuan tidak disebabkan oleh perbedaan biologis, tetapi merupakan bagian dari penindasan kelas yang berkuasa dalam relasi produksiyang diterapkan dalam konsep keluarga. Teori ini menekankan analisis gendernya dengan melihat hubungan laki-laki dan perempuan (suami-isteri) tidak ubahnya dengan hubungan proletar dan borjuis, hamba dan tuan, atau pemeras dan yang diperas. Dengan kata lain, ketimpangan peran gender dalam masyarakat bukan karena kodrat (nature), tetapi karenakonstruksi masyarakat (nurture).

Akhirnya pemikiran teoritis yang ditawarkan oleh teori koflik sosial dalam menganalisis marginalisasi sebenarnya difokuskan pada aspek hubungan gender (gender relation) yang dibangun di atas suasana konflik. Adapun hal yang dijadikan sebagai ajang konflik adalah sumber daya materi yang disebut sebagai kekuasaan. Dalam perebutan itu perempuan merupakan pihak yang lemah dan kalah sehingga dari sinilah muncul praktik eksploitasi 
dan dominasi laki-laki atas perempuan. Salah satu bentuk dari praktik eksploitasi dan dominasi itu diistilahkan sebagai marginalisasi terhadap perempuan di dalam berbagai struktur sosial di masyarakat terutama masyarakat yang patriarkis. Dengan adanya marginalisasi pada akhirnya mencerminkan pula terbentuknya suatu relasi gender yang bersifat timpang. Artinya; dalam hirarkhi kekuasaan perempuan menempati posisi kekuasaan yang rendah dan lemah dan sebaliknya laki-laki berada di posisi kekuasaan yang teratas dan kuat. Hal ini terjadi di keluarga, lembaga agama, ekonomi, hukum, politik dan lainnya.

Konsep marginalisasi maka Fakih (1996) dan Murniati (2004) mewakili pemikiran feminis di Indonesia menekankan marginalisasi sebagai salah satu dari manifestasi ketidakadilan gender. Mereka mengartikan marginalisasi sebagai proses yang mengakibatkan terjadinya kemiskinan atau pemiskinan pada atas satu jenis kelamin tertentu, dalam hal ini perempuan yang disebabkan karena gendernya. Ada beberapa perbedaan jenis dan bentuk, tempat dan waktu serta mekanisme proses marginalisasi kaum perempuan karena perbedaan gender tersebut. Dari segi sumbernya bisa berasal dari kebijakan pemerintah, keyakinan, tafsiran agama, keyakinan tradisi dan kebiasaan atau bahkan asumsi ilmu pengetahuan.

\section{METODOLOGI}

Peneliti menggunakan metode penelitian kualitatif dengan melakukan studi kasus. Creswell (2000) bahwa studi kasus yang mendeskripsikan dan menganalisa secara mendalam suatu fakta ataupun fenomena diimplementasikan melalui penelitian kualitatif baik dalam bentuk etnografi ataupun fenomenologi. Penelitian lapangan ini dilakukan oleh di kepulauan Nias dengan melakukan obeservasi di berbagai tempat yang dianggap telah mengalami marginalisasi adat perkawinan, serta mengadakan wawancara mendalam dengan perempuan keluarga-keluarga muda, terutama dalam hal jujuran. Penentuan Informan dalam penelitian ini menggunakan teknik purposive untuk mendapatkan data marginalisasi perempuan dalam tradisi adat perkawinan. Informasi ini masing-masing mewakili informasi perempuan maupun laki-laki sebagai satu kesatuan dalam penelitian.

\section{PEMBAHASAN}

Sebagai masyarakat Nias dikenal sangat teguh dalam memegang adat istiadat, masyarakat Nias hidup dengan berbagai aturan adat. Praktek adat sudah diatur dan disepakati bersama oleh tetua adat, khususnya dalam penentuan jujuran (mahar) adat perkawinan dengan pola kekerasan terhadap perempuan. Berdasarkan temuan penelitian bahwa adanya hubungan antara jujuran dengan kerentanan perempuan mengalami kekerasan dalam rumah 
tangga. Perempuan tidak dilibatkan dalam pengambilan keputusan pada awal menentukan jujuran yang hendak dimintakan kepada pihak laki-laki.

Berdasarkan data di atas memperlihatkan bahwa perempuan kurang terlibat dalam menentukan pasangan hidupnya. Bahkan ada trend baru dalam praktek perkawinan saat ini ialah sekalipun perempuan sudah memilih pasangan hidupnya, tetapi karena jujuran besar menjadi kendala utama dalam mewujudkan suatu pernikahan. Berikut hasil penuturan informan dalam kesempatan wawancara di tempat kerjanya.

“...Tergantung orangtua dan anak, tergantung adat, kalaupun orangtua mengerti, kalau sudah sama-sama mengerti walaupun anaknya sudah sekolah tinggi dan adat harus diikuti, dan juga sangat kurangnya orangtua dalam hal kebahagiaan orangtuanya, saya sendiri dengan ketidak cocokan jujuran, karena tidak setuju orangtua, makanya terjadi perkawinannya tidak sesuai adat, karena kebahagiaan saya dan keluarga saya" (Ani Waruwu).

Informan mengaku bahwa jujuran sangat tinggi di Nias, sebelum menikah di catatan sipil pernah ada laki-laki yang hendak melamar dirinya, tetapi karena orangtua meminta uang jujuran Rp 100.000.000 diluar kebutuhan yang lain. Akhirnya, pihak laki-laki tidak bisa menyanggupi uang dan lamaran tersebut tidak dilanjutkan, karena terkendala dengan jujuran.

Informan Gulo, mengaku jujuran pernikahan di Nias sangat membebankan. Ketika penentuan jujuran, ia pernah menyampaikan kepada sang ibu untuk tidak meminta jujuran yang tinggi. Namun masih antara ibu dan anak, serta belum bisa di depan keluarga besar. Ia mengaku bahwa penetuan jujuran saat ini sudah bergeser ke tingkat pendidikan. Ia berpesan agar dalam penetuan jujuran anak perempuan dilibatkan bisa langsung maupun tidak langsung.

Perempuan Nias belum mempunyai ruang untuk memperjuangkan haknya dalam penentuan jujuran. Bahkan ada kesan ada tidak perlu tahu apa yang dibicarakan oleh orangtua, padahal sebenarnya jujuran itu berkaitan dengan kehidupannya. Peneliti menduga bahwa sistem patriarki yang cukup kuat dalam adat masyarakat Nias menjadi kendala utama dalam memperjuangkan hak-hak perempuan Nias. Sinode Pertama Keusukupan Sibolga, menilai bahwa kerapuhan dalam relasi sosial bahkan mulia dari tingkat keluarga sendiri. Relasi yang tidak setara dan kasus KDRT disinyalir masih sering terjadi. Sistem patriarki yang sering meminggirkan perempuan dan anak-anak perempuan masih kuat berpengaruh (Sinode I, 2010:80).

Penuturan Daeli, dari pihak laki-laki menyadari hal itu sebagai kendala dalam mewujudkan keluarga harmoni. Bahkan secara implisit perempuan dalam sistem perkawinan zaman sekarang dikomersialkan dibuktikan dengan pergeseran istilah bowo ke goi-goila, artinya makna bowo yang dulunya sebagai kemurahan hati, kini menjadi tawar menawar. Studi Girsang (2014:21).di sekolah-sekolah di Nias juga menemukan hal yang sama terhadap anak perempuan di Nias: 
“Orangtua saya selalu menomorduakan saya sebagai perempuan karena kata mereka perempuan itu tidak bisa pergi jauh-jauh dan tidak bisa kerja di tempat yang lebih jauh, tetapi kalau adik saya laki-laki bisa saja, karena laki-laki bisa menjaga diri. Mereka berkata bahwa walaupun laki-laki "salah langkah", maka mereka bisa memperbaikinya. Tetapi jika perempuan satu kali "salah langkah", maka selamanya salah langkah".

Pengakuan di atas merupakan streotipe terhadap anak perempuan yang dianggap lemah, tidak bisa jaga diri, kurang bisa mengontrol diri, dan kerap berbuat salah sehingga disebut "salah langkah". Oleh karena itu perempuan harus dikontrol secara ketat, harus selalu dipantau. Gambaran streotipe dari perempuan adalah seorang yang lemah, emosional, sensitif, tergantung, pasif, submisif, luwe, memerlukan perlindungan dan sebagainya. Adapun streotipe laki-laki adalah memiliki fisik yang kuat, agresif, lebih rasional, ingin memimpin, melindungi, aktif, kompetitif, kaku, keras dan sebagainya (Munandar, SC Utami dalam Zubaedi, 2013: 231).

Penilain kritis dari tokoh agama, gereja memandang bahwa biaya pernikahan di Nias merupakan beban yang luar biasa, sehingga menjadi utang. Pihak Keuskupan Sibolga (Gereja Katolik) telah memberi pengertian yang sungguh-sungguh perlu untuk perkawinan, jadi dalam hal ini, itu lama kelamaan mulai banyak orang merasa bahwa praktek yang sekarang ini tidak sehat. Harus ada perubahan, jadi mulai ada usaha dari keuskupan, kadangkadang mereka mengeluh biaya besar, tapi kurang usaha untuk memberi penyadaran. Berikut hasil wawancara dengan salah satu imam misionaris yang sudah tinggal di Nias selama 19 tahun:

“... Di daerah ini agak tinggi dan di daerah lain juga. Tapi yang selalu membedakan biaya perkawinan atau böwö ya, yang membuat mahal dengan adanya alat-alat musik, dan ini kita coba agar supaya mereka yang barusan menikah jangan mendapat beban yang luar biasa. Yang menjadi sebuah ancaman beban bagi mereka untuk bertahun-tahun bekerja hanya untuk membayar-bayar utang mereka. (Wawancara dengan Pastor Mathias OSC).

Keterangan di atas memperlihatkan hubungan kemiskinan dengan jujuran tinggi dalam adat perkawinan di Nias. Dan ini menjadi dasar yang tidak bagus, menjadi ketegangan antara suami istri, kurang uang untuk menjamin anak baik sekolah, belum punya apa-apa, karena masih mencicil utang-utangnya. Jadi sebetulnya dalam perkawinan adat harusnya ada saling mencintai supaya tidak ada yang dirugikan, karena demikian biaya yang besar sekali itu sungguh-sunguh merugikan karena orangtua juga terkadang ingin mendapat penghargaan yang besar, namun yang menanggung nanti adalah anak mereka.

Akibat adat jujuran perkawinan di Nias berdampak pada kekerasan perempuan. Jujuran ini menjadi beban yang sangat-sangat berat, terlebih kalau 
mereka tidak beruntung, misalnya kalau tidak langsung usaha mereka tidak berjalan dengan baik, itu akan menjadi utang yang berat. Ini sangat tidak cocok, tidak tenang dan selalu di tagih. Beberapa langkah telah diadakan pertemuan kepada tokoh adat untuk melihat kembali jujuran adat pernikahan ini, gerakan ini juga dilakukan oleh keuskupan (gereja).

Ada kecenderungan orangtua tidak mempunyai uang untuk menikahkan anaknya laki-laki, tetapi karena pengaruh tetangga dengan menjanjikan meminjamkan uangnya, akhirnya ia menyetujui. Apabila tetangga itu tidak bisa menutupi kekurangan uang untuk biaya pesta tersebut, maka orangtua meminjam uang berbunga dengan bungan $5 \%$ (persen) dan bawi ondrauta (babi berbunga), biasanya dalam sebulan bertambah satu alisi per bulan. Tindakan ini lah yang akhirnya membawa dalam jurang kemiskinan, apalagi situasi ekonomi yang tidak menguntungkan. Maka solusi terakhir keluarga muda terpaksa pergi merantau di luar Pulau Nias, misalnya buruh perkebunan kelapa sawit di PT. Torganda.

Akibat mahalnya böwö, orangtua si anak bukan lagi bekerja untuk memenuhi kebutuhan keluarga dan anaknya, tapi mereka bekerja untuk membayar utang, membayar böwö yang dibebankan kepadanya. Bahkan utang böwö yang belum sempat terbayarkan oleh orangtua si anak mesti si anak harus bersedia membayarnya. Mahalnya böwö semakin diperparah sejak masyarakat Nias mengenal uang, karena böwö juga diuangkan. Mempelai laki-laki yang tidak mampu mencukupi nilai böwö yang harus ia bayar, tidak ada pilihan lain baginya selain meminjam. Singkatnya, lingkaran semacam inilah yang menyebabkan banyak keluarga Nias hanya bekerja untuk membayar bunga utang.

Penelitian (Purwanto, dkk, 2011:7), Migrasi pekerja Nias di perkebunan Riau juga disebabkan alasan adat yaitu tingginya mahar atau uang "jujuran" untuk perkawinan yang harus diberikan pihak laki-laki kepada pihak perempuan. Tidak jarang untuk memperoleh uang jujuran ini calon pengantin laki-laki harus menghutang pada pihak lain seperti kerabat, teman ataupun atasan. Karena di Nias lapangan pekerjaan terbatas dan sulit mendapatkan orang bisa memberikan pinjaman, terpaksa merantau ke luar daerah Nias.

\section{KESIMPULAN}

Proses marginalisasi perempuan dalam adat perkawinan tercermin juga dari pola relasi gender perempuan yang asimetris sebab perempuan berada pada posisi tawar yang lemah dalam hal mengambil keputusan baik di keluarga maupun. Pola relasi gender yang asimetris dalam keluarga diindikasikan dengan superioritas dan dominasi laki-laki dalam konteks suami dan ibu maupun saudara laki-laki mengambil keputusan strategis. Relasi gender yang asimetris dalam lembaga publik diindikasikan oleh dominasi lakilaki menduduki jabatan struktural dan sekaligus memposisikan mereka sebagai 
penentu keputusan (decision maker). Sebaliknya, perempuan hanya menempati posisi marginal (marginal power) dan berada di bawah kontrol dan dominasi laki-laki sehingga posisi mereka tersubordinasi mengambil keputusan di lembaga adat, pendidikan, ekonomi dan politik.

Perempuan dan perkawinan adat berdampak pada marginalisasi perempuan dalam rumah tangga. Perempuan masih belum mendapatkan kesamaan kedudukan dalam ruang publik. Perempuan masih dianggap nomor dua dalam keluarga itu terbukti dari jujuran yang dimintakan oleh orangtua. Selain itu, jujuran yang besar mengakibatkan pasangan suami isteri berutang turun temurun, dan bahkan tak jarang ada pernikahan di catatan sipil atau kawin lari yang merupakan fenomena baru dalam masyarakat Nias. Perhatian jujuran yang besar berdampak pada posisi perempuan dan kemiskinan menjadi keprihatinan bersama masyarakat Nias. Oleh sebab itu, pemerintah bersama tokoh agama harus mengadakan sosialisasi tentang jujuran adat perkawinan sebagai faktor kemiskinan secara terus menerus. Dalam hal ini bahwa budaya adat perkawinan Nias tidak perlu dihilangkan, tetapi disederhanakan nilai material böwö yang ada dalam pesta pernikahan.

\section{DAFTAR PUSTAKA}

\section{$\underline{\text { Buku }}$}

Abdullah, Irwan. 2001. Seks, Gender \& Reproduksi Kekuasaan. Yogyakarta: Tarawang.

Creswell, John W. 2002. Research Design, Desain Penelitian, Qualitative \& Quantitative Approaches (terjemahan) Alih bahasa: Angkatan III \&IV KIKUI dan bekerjasama dengan Nur Khabibah, Klik Press, Jakarta.

Fakih, Mansour. 1996. Analisis Gender dan Transformasi Sosial. Yogyakarta: Penerbit Pustaka Pelajar.

Girsang, Rio F. 2014. Nias dalam Perspektif Gender. Gunungsitoli: Caritas Keuskupan Sibolga.

Ihromi, Tapi Omas. 2000. Penghapusan Diskriminasi terhadap Wanita. Bandung: Penerbit Alumni.

Komnas Perempuan. 2009. Tak Hanya di Rumah; Pengalaman Perempuan akan Kekerasan di Pusaran Relasi Kekuasaan yang Timpang. Catatatan Ktp tahun 2009. Jakarta: Komnas Perempuan.

Megawangi, Ratna. 1999. Membiarkan Berbeda: Sudut Pandang Baru tentangRelasi Gender. Bandung: Mizan. Cet. I.

Purwanto, S.A., Haryono, Rokhdian, D., Handiko, K.B., Sugiharti, R., dan Erlangga, E., 2011. Asesmen Pendidikan dan Kajian Komuniti di Riau 
Program Pelita Pendidikan Yayasan Tanoto [Laporan Akhir]. Depok: Pusat Kajian Antropologi Universitas Indonesia.

Sinode I Keuskupan Sibolga. 2009. Gereja Mandiri, Solider dan Membebaskan: Rencana Strategis Pastoral 2010-2014. Sibolga: Kuskupan Sibolga.

Walby, Sylvia. 1990. Theorizing Patriarchy. Oxford: Basic Blackwell Ltd.

Wallace, Tina and Candida March. 1991. Changing Perception: Writing on Gender and Development. Oxford: Oxfam.

Zubaedi. 2013. Pengembangan Masyarakat: Wacana dan Praktik. Jakarta: Kencana.

Postinus Gulö. 2015. Böwö dalam Perkawinan Adat Öri Moro'ö Nias Barat. Bandung: Unpar Press. 